\title{
Evaluation of the performance of different firefly algorithms to the economic load dispatch problem in electrical power systems
}

\author{
Fatma Sayed Moustafa $^{1 *}$, N. M. Badra ${ }^{2}$, Almoataz Y. Abdelaziz $^{3}$ \\ ${ }^{1 *}, 2$ Department of Engineering Physics and Mathematics, Faculty of Engineering, Ain Shams University, Cairo, EGYPT \\ ${ }^{3}$ Department of Electrical Power and Machines, Faculty of Engineering, Ain Shams University, Cairo, EGYPT \\ "Corresponding Author: e-mail: fatima.sayed88@gmail.com, Tel +20-1002329974
}

\begin{abstract}
The planning, operation and control of electric power systems has attracted the attention of many researchers. Thus, effort is put in improving the efficiency of generation and operation of power plants. Economic load dispatch (ELD) is crucial since it is required to schedule committed generating units so as to meet load demand at minimum operating cost. In addition to satisfying all system equality and inequality constraints as well as limitations imposed on the generating units during operation. To solve the economic load dispatch problem, traditional and intelligent techniques were applied. Researchers have shown interest in utilizing metaheuristic methods to solve complex optimization problems in real life applications. In this paper, three alternatives of firefly algorithms are applied to solve the nonlinear ELD problem. A comparative study is carried out on the solution of ELD problem using those recent variants and the classical firefly algorithm for different test cases. Efficiency is evaluated by comparing best solutions obtained in terms of execution time, fuel cost and power loss.
\end{abstract}

Keywords: Economic load dispatch, Firefly algorithm, Modified firefly, Memetic firefly, and Variable step size firefly

DOI: http://dx.doi.org/10.4314/ijest.v9i2.1

\section{Introduction}

The operation and planning of electric power generation system is significant in the electric industry. Generation, transmission and distribution of electric power should be done efficiently, economically and optimally. The need to reduce the running charges of the electric energy became important due to the rise in fuel cost, expansion of the interconnected power systems and limited availability of generating units. Economic load dispatch (ELD) is a fundamental issue because as the power systems expand and cost of fuel increase, the need for determining optimal power output from generating units and minimizing operational cost grows. Economic load dispatch is the allocation of output power of the committed generating units optimally. This is done by generating optimum power, satisfying load demand and considering other operational system equality and inequality constraints. The ELD problem is a non-convex optimization problem since the input/output of generating units in real life are highly non-smooth and nonlinear. In addition, prohibited operating zone, ramp rate limits and multi-fuel options are usually considered. Since the objective is for the solution to converge to superior results in a reduced amount of time putting into consideration system constraints, choosing the appropriate optimization approach is important (Zhu et al., 2015).

Traditional mathematical optimization techniques like Linear Programming (LP) (Dhamanda et al., 2013), Quadratic Programming (QP) (Benhamida et al., 2013), Lambda Iteration (Lin et al., 1992), and Newton method (Jabr et al., 2000) were applied to solve the ELD problem. They have the advantage of being simple and fast. Nevertheless, they depend on initial points; sometimes they converge to the neighboring local optimal solution or even diverge. In addition, the solution of non-convex ELD problems is difficult and the computational effort it requires is enormous. To overcome the limitations of the traditional optimization techniques, metaheuristic methods were developed. These intelligent metaheuristic methods have shown fruitful success in solving the toughest nonlinear non convex optimization problems reaching feasible optimal solutions. Therefore, they have taken over conventional methods, becoming the best alternative choice for researchers in solving the ELD problem to ensure 
global solution with least computational effort. Examples of these intelligent metaheuristic methods are Simulated Annealing (SA) (Panigrahi et al., 2006), Differential Evolution (DE) (Noman and Iba, 2008), Genetic Algorithm (GA) (Sahoo et al., 2014), Particle Swarm Optimization (PSO), Ant Colony optimization (ACO), and Firefly Algorithm (FFA) (Moustafa et al., 2016).

The FFA is a developing optimization technique that is simple with a great ability to converge to optimum solutions faster than other intelligent methods (Subramanian and Thanushkodi, 2013; Younes, 2013). As a result, it is very useful when used in real time application making it suitable in solving the ELD problem. However, when dealing with complex optimization problems, the FFA shows deficiency in reaching global optima. It also doesn't save better-quality previous solutions and the parameters are not dynamic and the tuning of such parameters has proven to be a difficult task. It is a challenging task to solve complex optimization problems. Consequently, it is necessary to develop and enhance the optimization techniques. Although FFA has been widely applied to solve benchmark functions and numerous practical problems and has shown promise in finding optimal solutions, it has limitations in finding global optimum, especially when the complexity of the problem increases. Therefore, it became essential to propose modifications to the FFA and combining it with other intelligent techniques and creating new hybrids, hence, obtain efficient and reliable solutions (Fister et al., 2013). Modifications include and not restricted to: adding memory, varying parameters of the algorithm throughout the iterations and altering the updating formula for the fireflies. New variants of FFA were proposed and implemented to solve benchmark functions, engineering design problems, economic load dispatch problems and so on (Kazemzadah-Parsi, 2014; FisterJr et al., 2012, Yu et al., 2015; Farhani et al., 2011; Gandomi et al., 2013; Yu et al., 2014). Some of these new versions of firefly algorithm recently developed, but not yet applied to solve the ELD problem like modified firefly algorithm(MFA), memeticfirefly algorithm (MFFA) and variable step size firefly algorithm (VSSFA) (Kazemzadah-Parsi, 2014; FisterJr et al., 2012, Yu et al., 2015). In this paper, these three variants are applied to solve the nonlinear ELD problem. A comparative study was carried out on the solution of ELD problem using those recent variants and the classical FFA for different test cases. Efficiency was evaluated by comparing best solutions obtained in terms of execution time, fuel cost and power loss.

\section{Problem Formulation}

The objective of the nonlinear ELD optimization problem is to minimize cost while satisfying the load demand and other operational system equality and inequality constraints (Zhu et al., 2015).

2.1 Objective function- cost function

Minimize

where

$$
\begin{aligned}
& F_{T}=F\left(P_{i}\right)=\sum_{i=1}^{N g} F_{i}\left(P_{i}\right) \$ / h r \\
& F_{i}\left(P_{i}\right)=a_{i}+b_{i} P_{i}+c_{i} P_{i}^{2} \$ / h r
\end{aligned}
$$

FT: Total Quadratic cost function; it could be also a cubic function

$\mathrm{P}_{\mathrm{i}}$ : Real power generated

$\mathrm{N}_{\mathrm{g}}$ : Number of generation busses

$\mathrm{a}_{\mathrm{i}}, \mathrm{b}_{\mathrm{i}}, \mathrm{c}_{\mathrm{i}}$ : Fuel cost coefficients for $\mathrm{i}^{\text {th }}$ unit

\subsection{Constraints}

The objective function must be minimized while considering the following constraints:

1) Equality constraint- Energy balance equation

$$
\begin{aligned}
& \sum_{i=1}^{N_{g}} P_{i}=P_{D}+P_{L} \\
& P_{L}=\sum_{i=1}^{N_{g}} \sum_{j=1}^{N_{g}} P_{i} B_{i j} P_{j}
\end{aligned}
$$

where

$\mathrm{P}_{\mathrm{D}}=$ Load demand

$\mathrm{P}_{\mathrm{L}}=$ Power transmission losses

$\mathrm{B}_{\mathrm{ij}}=$ Loss coefficients (constants)

$\mathrm{P}_{\mathrm{i}}, \mathrm{P}_{\mathrm{j}}=$ Active power injection at the $\mathrm{i}^{\text {th }}$ and $\mathrm{j}^{\text {th }}$ generators

In some cases, power losses are neglected and the active power balance equation becomes:

$$
\sum_{i=1}^{N_{g}} P_{i}=P_{D}
$$

2) Inequality constraint- Generating limits

Generated active power should lie between minimum and maximum operational values

where

$$
P_{i}^{\min } \leq P_{i} \leq P_{i}^{\max }
$$

$\mathrm{P}_{\mathrm{i}}=$ Power output from generator (i)

$\mathrm{P}_{\mathrm{i}}^{\text {min }}=$ Minimum permitted power output by generator (i)

$\mathrm{P}_{\mathrm{i}}{ }^{\max }=$ Maximum permitted power output by generator (i) 


\section{Firefly Algorithm}

Firefly algorithm is a recent nature based metaheuristic developed by Yang to solve the continuous optimization problems. The idea behind FFA is that fireflies emit light produced by chemical reactions. The light flashing behavior attracts fireflies to each other for mating purposes (Yang, 2008).

To simulate such idyllic behavior, some rules must be followed:

a) Fireflies are assumed to be unisex. Attraction of fireflies doesn't depend on their sex, but depend only on their brightness.

b) The brightness of a firefly is determined by the objective function

c) Attractiveness is directly proportional to brightness and both are inversely proportional to distance

Using Firefly algorithm in optimization problems, light intensity and brightness represents the objective function and the attraction and movement towards the brightest firefly resembles reaching optimal solution. The factors affecting the algorithm are light intensity, attractiveness, distance, and movement and are given by:

$$
\begin{aligned}
& \text { Light intensity } I(r)=I_{0} e^{-\gamma r^{2}} \\
& \text { Attractiveness } \beta(r)=\beta_{0} e^{-\gamma r^{2}}
\end{aligned}
$$

where $I_{0}$ and $\beta_{0}$ are the initial light intensity and initial brightness, respectively.

This distance between firefly $\mathrm{i}$ and firefly $\mathrm{j}$ is represented as:

$$
r_{i j}=\left\|x_{i}-x_{j}\right\|=\sqrt{\sum_{k=1}^{d}\left(x_{i k}-x_{j k}\right)^{2}}
$$

The formula that controls the fireflies' movement is given by:

$$
x_{i}^{t+1}=x_{i}^{t}+\beta_{0} e^{-\gamma r_{i j}^{2}}\left(x_{j}^{t}-x_{i}^{t}\right)+\alpha(\text { rand }-0.5)
$$

where $t$ is the number of current iteration, $\alpha \in[0,1]$ is the randomization parameter and $\gamma \in[0, \infty)$ is the coefficient of absorption. The first term is the current position of the firefly $i$, the second term is due to attraction towards a brighter firefly $j$ and the last term represents the random walk of the firefly.

\section{A. Variants of Firefly Algorithm}

Since FFA was developed, it has become a popular optimizer. It has been widely applied to solve benchmark functions and numerous practical problems. Although the FFA has shown promise in finding optimal solutions, it has limitations in finding the global optimum, especially when the complexity of the problem increases. In recent studies, major improvements and changes were applied to the FFA to enhance its performance. New variants of FFA were proposed and implemented to solve benchmark functions, engineering design problems and so on (Kazemzadah-Parsi, 2014; FisterJr et al., 2012; Yu et al., 2015; Farhani et al., 2011; Gandomi et al., 2013; Yu et al., 2014).

Gaussian firefly was developed by (Farhani et al., 2011). Gaussian distribution was used to control the random movement of fireflies so they are directed to the global solution. Firefly with chaos was proposed by (Gandomi et al., 2013). Chaos was introduced to FFA for a more efficient global optimization. Wise step size firefly algorithm was developed by (Yu et al., 2014). Parameter $\alpha$ is controlled by global best position and vary dynamically with iterations. Modified firefly algorithm was presented by (Kazemzadah-Parsi, 2014). The updating formula is adjusted, memory is added and newborn fireflies are added in each iteration. Memetic firefly was developed by (FisterJr et al., 2012). It was applied to combinatorial problems. Instead of having fixed parameters $\alpha$ and $\beta$, these parameters are dynamically fine-tuned and the random movement is scaled as well. Variable step size firefly algorithm was used by (Yu et al., 2015). Parameter $\alpha$ varies dynamically with the iterations.

\section{B. Modified Firefly Algorithm}

Modified firefly algorithm was presented by (Kazemzadah-Parsi, 2014). Updating formula is adjusted, memory is added and newborn fireflies are added in each iteration.

Three new modifications were suggested: adding memory, newborn fireflies and updating formula.

a) Adding memory: Two approaches are considered in the adding memory modification.

1. $\left(\mathrm{m}_{1}\right)$ high quality solution fireflies are not updated and transferred to the following iterations. The rest of the fireflies $\left(n-m_{1}\right)$ are updated using a new updating formula discussed later. 
2. $\left(\mathrm{m}_{2}\right)$ high quality solution fireflies are copied and saved from the current iteration. In the next iteration, $\left(\mathrm{m}_{2}\right)$ low quality solution fireflies are exchanged by the $\left(\mathrm{m}_{2}\right)$ high quality solution fireflies saved from the preceding iteration.

In our work only the second approach is implemented.

b) Newborn fireflies: (k) low quality solution fireflies are exchanged by (k) randomly generated fireflies within the search space.

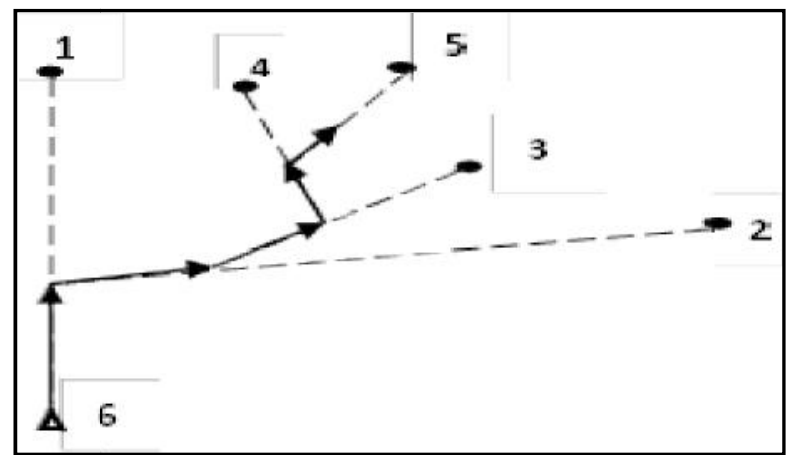

Figure 1. Schematic diagram that shows the zigzag path that firefly (6) takes to approach the five more luminous fireflies than itself. Its location is updated in five steps.

c) Updating formula: The strategy implemented by the original firefly algorithm is that the fireflies to reach the optimum solution by taking steps towards the brightest firefly, then a step towards the second bright and so on. The fireflies approached brighter ones in a zigzag like path.

Depending on the value of objective function, the six fireflies arranged. Firefly (1) is the most luminous and firefly (6) is the least luminous. In the first iteration to update the location of firefly (6), it approaches firefly (1) since it is the brightest. During the second iteration, firefly (6) approaches firefly (2) since it is the second bright, and thus; its location is updated. During the upcoming iterations, the former steps are repeated until there no fireflies brighter than firefly (6) as shown in Figure1. The number of steps each firefly takes to update its location is equal to the number of more luminous fireflies than itself.

This approach is ineffective, requires more computational time and affects the performance of the algorithm negatively.The modification to this time consuming approach suggests that a point representing the general overall location of the more luminous fireflies is calculated as shown in Figure 2. The representation proposed in our study is to calculate the mean location of the more luminous fireflies. This mean point $\left(\mathrm{P}_{\mathrm{i}}\right)$ that represents the mean coordinates of fireflies more luminous than firefly (i) is given by the following formula:

$$
\begin{aligned}
& P_{i}=\frac{1}{i-1} \sum_{k=1}^{i-1} x_{k} \\
& r_{i}=\left\|P_{i}-x_{i}\right\|
\end{aligned}
$$

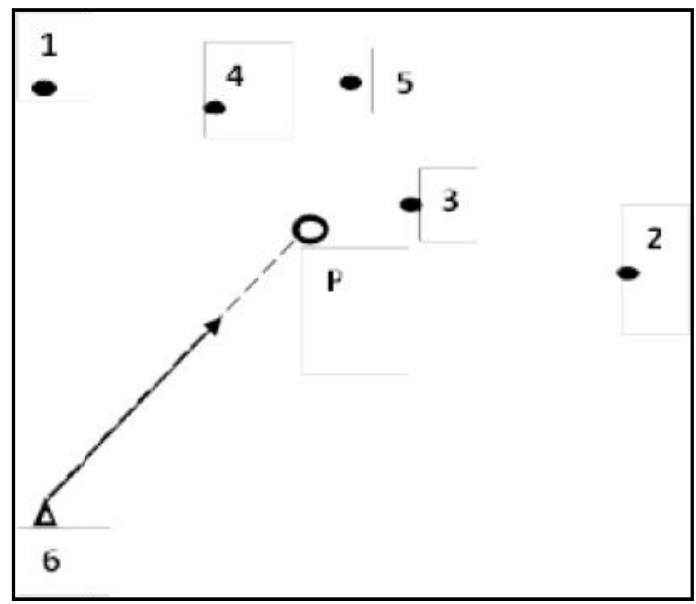

Figure 2. Schematic diagram illustrating the mean point $(\mathrm{P})$ that represents the mean coordinates of fireflies more luminous than firefly (6). Its location is updated in only one step and thus changing the updating formula with a scaled random movement to be: 


$$
x_{i}^{t+1}=x_{i}^{t}+\beta\left(P_{i}^{t}-x_{i}^{t}\right)+\alpha \varepsilon
$$

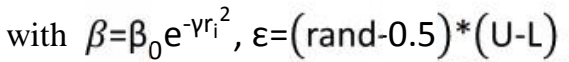

where $\mathrm{U}$ and $\mathrm{L}$ are the upper and lower bounds of the search space, respectively.

\section{Memetic Firefly Algorithm}

Memetic firefly was developed by (Fister et al., 2012). The MFFA was applied on combinatorial problems. Instead of having fixed parameters $\alpha$ and $\beta$, these parameters are dynamically fine-tuned and the random movement is scaled as well. Memetic algorithm (MA) attains the balance between diversity and intensity of solution in search space. Diversification (randomness) allows fireflies to wander in search space and not cluster near local optima. Intensification allows fireflies to smoothly converge to the global optimal solution. Such balance utilizes global and local search to obtain optimal solutions effectively. MFFA combines the balance of search in memetic algorithms and the superiority of firefly algorithm compared to other methods. Memetic firefly algorithm can solve problems with high dimensions and various strategies were proposed. High diversification can lead to inefficient search and high intensification can lead to converging prematurely.

$\alpha$ is adjusted dynamically by:

where

$$
\alpha=\alpha\left(\frac{1}{9000}\right)^{\frac{1}{t}} *(U-L)
$$

$\alpha$ is initially set to 0.2

$\mathrm{t}=$ number of current iteration

$\mathrm{U}=$ upper bound of the search space

$\mathrm{L}=$ lower bound of the search space.

$\beta$ changes in the range $[0.2,1]$ using this formula:

where $\beta_{\min }=0.2$ and $\beta_{0}=1$

$$
\beta=\beta_{\text {min }}+\left(\beta_{0}-\beta_{\text {min }}\right) e^{-\gamma r_{i j}^{2}}
$$

and thus changing the updating formula with a scaled random movement to be:

$$
x_{i}^{t+1}=x_{i}^{t}+\beta\left(x_{j}^{t}-x_{i}^{t}\right)+\alpha(\text { rand }-0.5) *(U-L)
$$

where $\mathrm{U}$ and $\mathrm{L}$ are the upper and lower bounds of search space, respectively.

\section{Variable Step Size Firefly Algorithm}

Variable step size firefly algorithm was used by (Yu et al., 2015). Parameter $\alpha$ varies dynamically with the iterations. The parameters of the firefly algorithm are kept fixed. The balance between global and local search is controlled by the randomization parameter or step size $\alpha$. Such balance is affected by keeping this parameter unchangeable. The initial iterations should encourage exploring possible solutions in the search space. Therefore, a larger $\alpha$ initially is required to evade local optimum. As the iterations go on, a smaller $\alpha$ is more appropriate to exploit the neighborhood of prospective solutions. The decreasing of step size $\alpha$ as iterations proceed guarantees convergence to global optimal solution efficiently. In the variable step size firefly algorithm (VSSFA), step size $\alpha$ is adjusted dynamically as iterations progress.

The step size $\alpha$ formula given by the following formula:

$$
\alpha(k)=\frac{0.4}{1+\exp (0.005 *(k-\text { MaxGeneration }))}
$$

where

$\mathrm{k}$ : the current iteration

MaxGeneration: the total number of iterations.

\section{Test and Results}

The FFA and its three variants explained in the preceding chapter are applied on the ELD problem of three units systems. The number of fireflies, maximum number of iterations, light absorption coefficient and initial brightness are the same for the firefly algorithm and its variants. The randomization parameter is different for each application. Memory and newborn parameters are given for the MFA. Minimum brightness is given for the MFFA. The best and mean solutions and standard deviation of twenty independent runs are calculated in each application. The best solutions, time of execution and the statistical results were evaluated and analyzed. Comparisons of the results obtained by firefly algorithm, its variants and other techniques mentioned in literature were carried out (Reddy and Reddy, 2012; Sudhakaran et al., 2007; Tiwari et al., 2013). 
Table 1. Parameters for firefly algorithm and its variants

\begin{tabular}{|c|c|c|c|c|}
\hline \multirow{2}{*}{ Parameters } & \multicolumn{4}{|c|}{ Values for different algorithms } \\
\cline { 2 - 5 } & $F F A$ & $M F A$ & $V S S F A$ & $M F F A$ \\
\hline MaxGeneration & 150 & 150 & 150 & 150 \\
\hline $\mathrm{n}$ & 25 & 25 & 25 & 25 \\
\hline$\alpha$ & 0.2 & 0.2 & Varies with iterations & Initially $\alpha=0.2$ but decreases with iterations \\
\hline$\gamma$ & 1 & 1 & 1 & 1 \\
\hline$\beta_{0}$ & 1 & 1 & 1 & 1 \\
\hline$\beta_{\min }$ & NA & NA & NA & NA \\
\hline $\mathrm{m}_{1}$ & NA & 0 & NA & NA \\
\hline $\mathrm{m}_{2}$ & NA & 1 & NA & NA \\
\hline $\mathrm{k}$ & NA & 1 & NA & \\
\hline
\end{tabular}

The cost functions to be minimized for the three thermal units are given as follows:

$$
\begin{aligned}
& F_{1}=561+7.92 P_{1}+0.001562 P_{1}{ }^{2} \$ / h r \\
& F_{2}=310+7.85 P_{2}+0.001940 P_{2}{ }^{2} \$, h r \\
& F_{3}=78+7.97 P_{3}+0.004820 P_{3}{ }^{2} \$ / h r
\end{aligned}
$$

Real power limits:

$$
\begin{aligned}
& 100 \leq P_{1} \leq 600 \\
& 100 \leq P_{2} \leq 400 \\
& 40 \leq P_{3} \leq 200 \\
& P_{D}+P_{L}=P_{1}+P_{2}+P_{3}
\end{aligned}
$$

Loss coefficient $\mathrm{B}_{\mathrm{ij}}$

$$
B_{i j}=\left[\begin{array}{ccc}
0.000075 & 0.000005 & 0.0000075 \\
0.000005 & 0.000015 & 0.00001 \\
0.0000075 & 0.00001 & 0.000045
\end{array}\right]
$$

\subsection{Transmission losses not included}

The power distribution, cost and time for the best solution obtained by the different approaches for different power demands are given in the Tables (2-7). The reliability analyses for twenty independent runs are given in the Tables $(8-13)$.

The comparisons between best cost and time of execution for the FFA, its variants and GA are given in Table (14) and Figures (34).

Table 2. Solution for power demand $=450 \mathrm{MW}$

\begin{tabular}{|c|c|c|c|c|}
\hline & FFA & MFA & VSSFA & MFFA \\
\hline P1 & 210.9323 & 205.5350 & 202.7603 & 204.1462 \\
\hline P2 & 178.5729 & 183.0785 & 183.7123 & 183.7871 \\
\hline P3 & 60.4947 & 61.3865 & 63.5275 & 62.0667 \\
\hline Cost & 4652.5 & 4652.4 & 4652.5 & 4652.4 \\
\hline Time(seconds) & 0.498447 & 0.078653 & 0.524861 & 0.217412 \\
\hline
\end{tabular}

Table 3. Solution for power demand $=585 \mathrm{MW}$

\begin{tabular}{|c|c|c|c|c|}
\hline & FFA & MFA & VSSFA & MFFA \\
\hline P1 & 266.6992 & 269.3735 & 267.6083 & 267.2763 \\
\hline P2 & 238.3142 & 233.6227 & 234.6370 & 234.5635 \\
\hline P3 & 79.9866 & 82.0038 & 82.7547 & 83.1602 \\
\hline Cost & 5821.6 & 5821.6 & 5821.6 & 5821.6 \\
\hline Time(seconds) & 0.514214 & 0.078843 & 0.533350 & 0.212202 \\
\hline
\end{tabular}

Table 4. Solution for power demand $=600 \mathrm{MW}$

\begin{tabular}{|c|c|c|c|c|}
\hline & FFA & MFA & VSSFA & MFFA \\
\hline P1 & 275.6610 & 276.3577 & 271.5320 & 276.2698 \\
\hline P2 & 242.0674 & 239.6248 & 244.0853 & 239.4353 \\
\hline
\end{tabular}


Moustafa et al. / International Journal of Engineering, Science and Technology, Vol. 9, No. 2, 2017, pp. 1-14

\begin{tabular}{|c|c|c|c|c|}
\hline P3 & 82.2716 & 84.0175 & 84.3827 & 84.2950 \\
\hline Cost & 5953.2 & 5953.1 & 5953.2 & 5953.1 \\
\hline Time(seconds) & 0.509636 & 0.077439 & 0.532048 & 0.199898 \\
\hline
\end{tabular}

Table 5. Solution for power demand $=700 \mathrm{MW}$

\begin{tabular}{|c|c|c|c|c|}
\hline & FFA & MFA & VSSFA & MFFA \\
\hline P1 & 326.3860 & 323.1222 & 320.9296 & 322.6530 \\
\hline P2 & 275.7047 & 278.1399 & 276.2013 & 277.9427 \\
\hline P3 & 97.9093 & 98.7379 & 102.8691 & 99.4043 \\
\hline Cost & 6838.7 & 6838.6 & 6838.7 & 6838.6 \\
\hline Time(seconds) & 0.508926 & 0.079287 & 0.552621 & 0.207671 \\
\hline
\end{tabular}

Table 6. Solution for power demand $=800 \mathrm{MW}$

\begin{tabular}{|c|c|c|c|c|}
\hline & FFA & MFA & VSSFA & MFFA \\
\hline P1 & 366.1402 & 368.0085 & 372.5973 & 368.5635 \\
\hline P2 & 318.9648 & 317.0630 & 314.0788 & 316.6006 \\
\hline P3 & 114.8950 & 114.9284 & 113.3239 & 114.8359 \\
\hline Cost & 7738.8 & 7738.8 & 7738.8 & 7738.8 \\
\hline Time(seconds) & 0.515501 & 0.078750 & 0.545341 & 0.212810 \\
\hline
\end{tabular}

Table 7. Solution for power demand $=900 \mathrm{MW}$

\begin{tabular}{|c|c|c|c|c|}
\hline & FFA & MFA & VSSFA & MFFA \\
\hline P1 & 413.4513 & 415.4486 & 414.8906 & 416.6916 \\
\hline P2 & 355.9829 & 354.6639 & 352.8460 & 353.4335 \\
\hline P3 & 130.5658 & 129.8874 & 132.2634 & 129.8749 \\
\hline Cost & 8653.6 & 8653.6 & 8653.6 & 8653.6 \\
\hline Time(seconds) & 0.517866 & 0.079307 & 0.555965 & 0.214578 \\
\hline
\end{tabular}

The cost of fuel and time of execution is minimal for both the MFA and MFFA. However, the time of execution for the MFA is less than that of the MFFA. Time of execution of VSFFA is maximal in this case.

Table 8. Reliability analysis for power demand $=450 \mathrm{MW}$

\begin{tabular}{|c|c|c|c|c|}
\hline & FFA & MFA & VSSFA & MFFA \\
\hline Best & 4652.5 & 4652.4 & 4652.5 & 4652.4 \\
\hline Mean & 4654.57 & 4652.4 & 4653.945 & 4653.02 \\
\hline$S D$ & 2.342535738 & 0 & 1.4964783 & 0.900643 \\
\hline
\end{tabular}

Table 9. Reliability analysis for power demand $=585 \mathrm{MW}$

\begin{tabular}{|c|c|c|c|c|}
\hline & FFA & MFA & VSSFA & MFFA \\
\hline Best & 5821.6 & 5821.6 & 5821.6 & 5821.6 \\
\hline Mean & 5824.465 & 5812.6 & 5823.495 & 5822.045 \\
\hline SD & 1.9107108 & 0 & 1.5669195 & 0.9389103 \\
\hline
\end{tabular}

Table 10. Reliability analysis for power demand $=600 \mathrm{MW}$

\begin{tabular}{|c|c|c|c|c|}
\hline & FFA & MFA & VSSFA & MFFA \\
\hline Best & 5953.2 & 5953.1 & 5953.2 & 5953.1 \\
\hline Mean & 5955.05 & 5953.12 & 5953.965 & 5953.425 \\
\hline$S D$ & 1.6410844 & 0.0410391 & 0.7125012 & 0.7946366 \\
\hline
\end{tabular}

Table11. Reliability analysis for power demand $=700 \mathrm{MW}$

\begin{tabular}{|c|c|c|c|c|}
\hline & FFA & MFA & VSSFA & MFFA \\
\hline Best & 6838.7 & 6838.6 & 6838.7 & 6838.6 \\
\hline Mean & 6839.92 & 6838.6 & 6840.025 & 6838.7 \\
\hline SD & 1.8019288 & 0 & 1.3633839 & 0.2655679 \\
\hline
\end{tabular}


Table 12. Reliability analysis for power demand $=800 \mathrm{MW}$

\begin{tabular}{|c|c|c|c|c|}
\hline & FFA & MFA & VSSFA & MFFA \\
\hline Best & 7738.8 & 7738.8 & 7738.8 & 7738.8 \\
\hline Mean & 7742.865 & 7738.8 & 7742.175 & 7739.03 \\
\hline$S D$ & 2.9462331 & 0 & 2.120793 & 0.6009641 \\
\hline
\end{tabular}

Table 13. Reliability analysis for power demand = 900MW

\begin{tabular}{|c|c|c|c|c|}
\hline & FFA & MFA & VSSFA & MFFA \\
\hline Best & 8653.6 & 8653.6 & 8653.6 & 8653.6 \\
\hline Mean & 8656.5011 & 8653.6 & 8656.085 & 8653.605 \\
\hline$S D$ & 3.2084989 & 0 & 2.3611494 & 0.0223607 \\
\hline
\end{tabular}

The result obtained by MFA is the most stable and the FFA is the least stable. MFFA is more stable than VSSFA.

Table 14. Comparing cost for different power demands with Genetic Algorithm

\begin{tabular}{|c|c|c|c|c|c|}
\hline Power demand & GA & FFA & MFA & VSSFA & MFFA \\
\hline 585 & 5827.5 & 5821.6 & 5821.6 & 5821.6 & 5821.6 \\
\hline 700 & 6877.2 & 6838.7 & 6838.6 & 6838.7 & 6838.6 \\
\hline 800 & 7756.8 & 7738.8 & 7738.8 & 7738.8 & 7738.8 \\
\hline
\end{tabular}

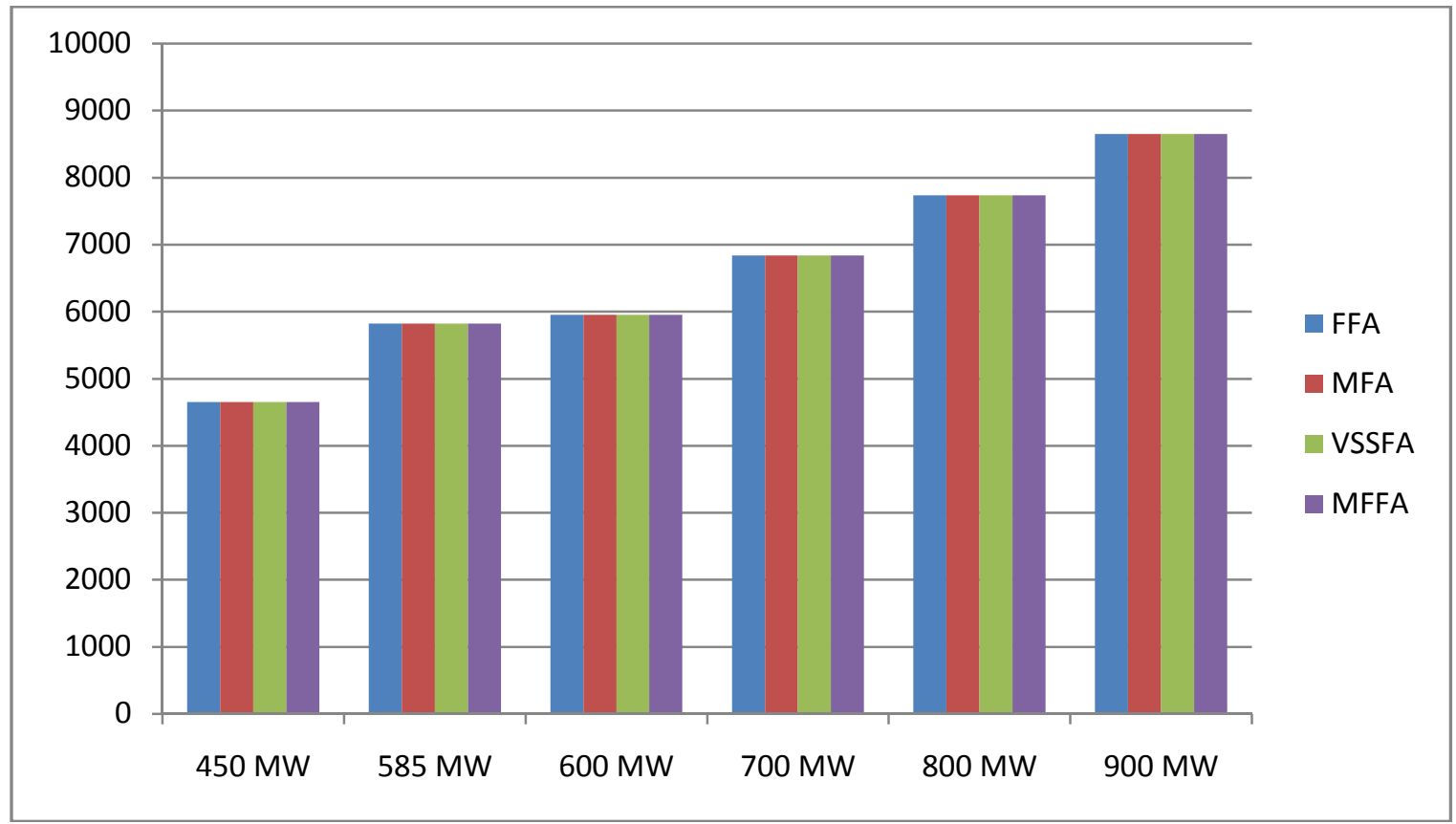

Figure 3. Comparing cost for different power demands 


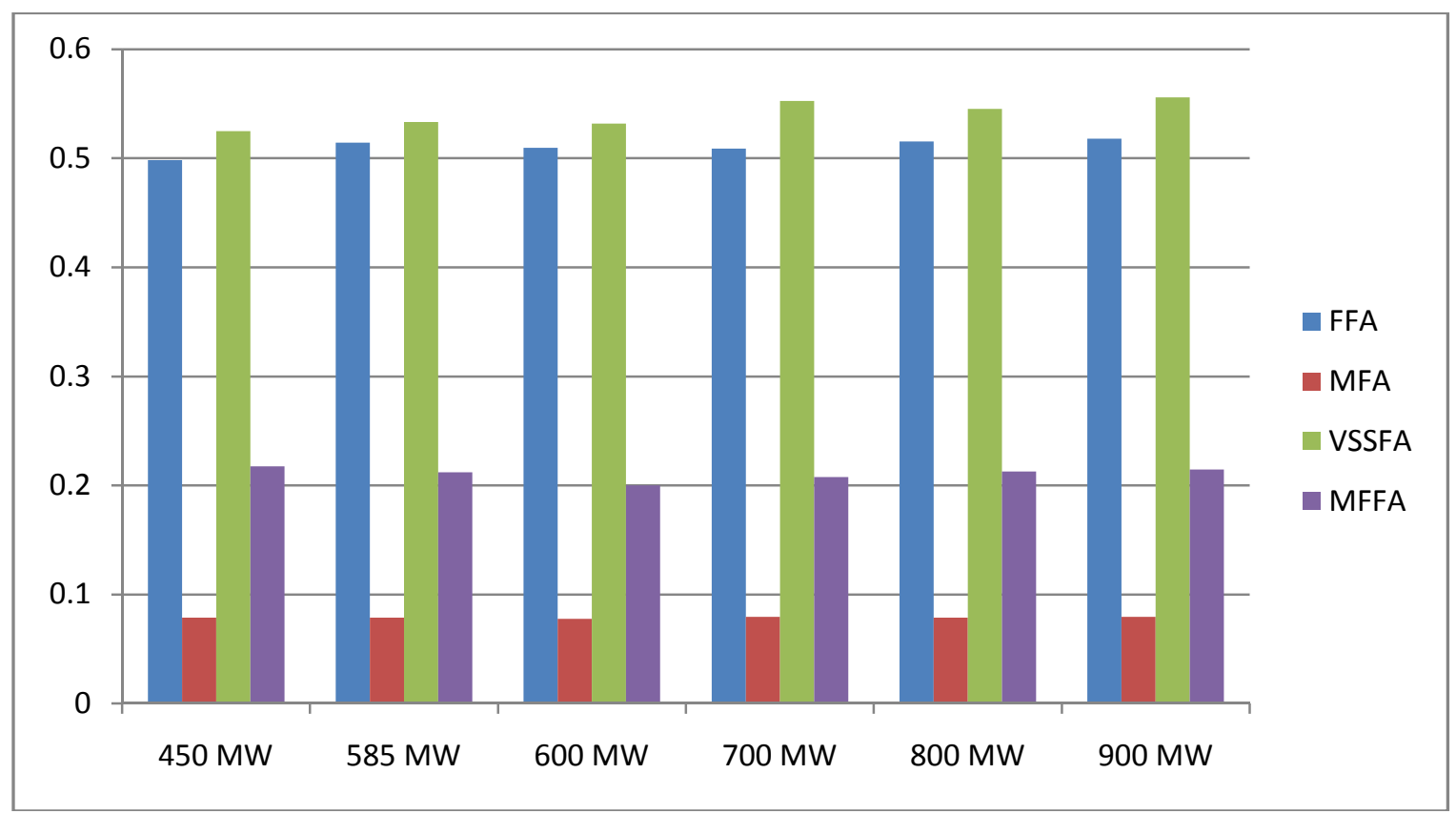

Figure 4. Comparing time for different power demands

As shown in the above table and figures FFA achieves better solution than GA in terms of minimum cost. The difference in cost between FFA and its variants is not significant. However, the MFA is almost 6.5 times faster than the FFA. The MFFA is almost 2.5 times faster than FFA.

\subsection{Transmission losses included}

The power distribution, cost, time and power losses for the best solution obtained by the different approaches for different power demands are given in the Tables $(15-18)$. The reliability analyses for twenty independent runs are given in the Tables (19-22). The comparisons between best cost time of execution and power losses of FFA, its variants and PSO are given in Tables (23 - 24) and Figures $(5-7)$.

Table 15. Solution for power demand $=585 \mathrm{MW}$

\begin{tabular}{|c|c|c|c|c|}
\hline & FFA & MFA & VSSFA & MFFA \\
\hline P1 & 229.8586 & 233.1711 & 227.2825 & 232.9819 \\
\hline P2 & 265.1271 & 268.1007 & 273.4247 & 267.9658 \\
\hline P3 & 96.9115 & 90.6825 & 91.0920 & 91.0032 \\
\hline Ploss & 6.8971 & 6.0667 & 6.7993 & 6.9509 \\
\hline Cost & 5887.3 & 5887.0 & 5887.2 & 5887.0 \\
\hline Time(seconds) & 2.410235 & 0.344904 & 2.710710 & 0.603812 \\
\hline
\end{tabular}

Table 16. Solution for power demand $=600 \mathrm{MW}$

\begin{tabular}{|c|c|c|c|c|}
\hline & FFA & MFA & VSSFA & MFFA \\
\hline P1 & 241.6172 & 238.4055 & 233.3197 & 235.0256 \\
\hline P2 & 272.9669 & 275.0288 & 281.1677 & 277.9416 \\
\hline P3 & 92.8020 & 93.8673 & 92.6692 & 94.2434 \\
\hline Ploss & 7.3861 & 6.3111 & 7.1566 & 7.2106 \\
\hline Cost & 6022.3 & 6022.3 & 6022.4 & 6022.3 \\
\hline Time(seconds) & 2.461330 & 0.358319 & 2.625015 & 0.661870 \\
\hline
\end{tabular}

Table 17. Solution for power demand $=700 \mathrm{MW}$

\begin{tabular}{|c|c|c|c|c|}
\hline & FFA & MFA & VSSFA & MFFA \\
\hline P1 & 282.9725 & 279.9986 & 276.4951 & 27808975 \\
\hline P2 & 312.8414 & 318.9859 & 316.2038 & 320.3834 \\
\hline P3 & 114.3339 & 111.0446 & 117.2554 & 110.7102 \\
\hline Ploss & 10.1477 & 8.8288 & 9.9543 & 9.9911 \\
\hline
\end{tabular}




\begin{tabular}{|c|c|c|c|c|}
\hline Cost & 6935.1 & 6934.9 & 6935.2 & 6934.9 \\
\hline Time(seconds) & 2.443697 & 0.330166 & 2.692303 & 0.622944 \\
\hline
\end{tabular}

Table 18. Solution for power demand $=800 \mathrm{MW}$

\begin{tabular}{|c|c|c|c|c|}
\hline & FFA & MFA & VSSFA & MFFA \\
\hline P1 & 319.7665 & 319.8415 & 316.4809 & 318.4764 \\
\hline P2 & 363.9400 & 365.1622 & 366.1312 & 366.1738 \\
\hline P3 & 129.4296 & 128.1260 & 130.4087 & 128.4306 \\
\hline Ploss & 13.1361 & 11.7293 & 13.0208 & 13.0808 \\
\hline Cost & 7867.5 & $7867.4 \mathrm{e}$ & 7867.5 & 7867.4 \\
\hline Time(seconds) & 2.422965 & 0.324316 & 2.608767 & 0.752689 \\
\hline
\end{tabular}

The minimum fuel cost and least execution time are achieved by both the MFA and MFFA. However, MFA is faster than MFFA. The best solution obtained by VSSFA is the worst in terms of execution time and minimum cost.

Table 19. Reliability analysis for power demand $=585 \mathrm{MW}$

\begin{tabular}{|c|c|c|c|c|}
\hline & FFA & MFA & VSSFA & MFFA \\
\hline Best & 5887.3 & 5887.0 & 5887.2 & 5887.0 \\
\hline Mean & 5890.245 & 5887.09 & 5888.865 & 5887.375 \\
\hline$S D$ & 2.5351165 & 0.0307794 & 1.5218669 & 1.1433446 \\
\hline
\end{tabular}

Table 20. Reliability analysis for power demand =600MW

\begin{tabular}{|c|c|c|c|c|}
\hline & FFA & MFA & VSSFA & MFFA \\
\hline Best & 6022.3 & 6022.3 & 6022.4 & 6022.3 \\
\hline Mean & 6025.5 & 6022.3 & 6024.245 & 6022.625 \\
\hline$S D$ & 3.6103652 & 0 & 1.493662 & 0.6239728 \\
\hline
\end{tabular}

Table 21. Reliability analysis for power demand =700MW

\begin{tabular}{|c|c|c|c|c|}
\hline & FFA & MFA & VSSFA & MFFA \\
\hline Best & 6935.1 & 6934.9 & 6935.2 & 6934.9 \\
\hline Mean & 6937.745 & 6934.915 & 6936.75 & 6935.13 \\
\hline SD & 2.3209515 & 0.0366348 & 1.2492103 & 0.6375116 \\
\hline
\end{tabular}

Table 22. Reliability analysis for power demand =800MW

\begin{tabular}{|c|c|c|c|c|}
\hline & FFA & MFA & VSSFA & MFFA \\
\hline Best & 7867.5 & $7867.4 \mathrm{e}$ & 7867.5 & 7867.4 \\
\hline Mean & 7869.84 & 7867.4 & 7869.935 & 7867.915 \\
\hline SD & 3.5845282 & 0 & 2.4009373 & 0.5294237 \\
\hline
\end{tabular}

The variants of firefly algorithm are more stable the FFA. MFA is the more stable than MFFA and MFFA is more stable than VSFFA.

Table 23. Comparing cost for different power demands with particle swarm algorithm

\begin{tabular}{|c|c|c|c|c|c|}
\hline Power demand & PSO & FFA & MFA & VSSFA & MFFA \\
\hline 585 & 5889.9 & 5887.3 & 5887.0 & 5887.2 & 5887.0 \\
\hline
\end{tabular}

Table 24. Comparing loss for different power demands with particle swarm algorithm

\begin{tabular}{|c|c|c|c|c|c|}
\hline Power demand & PSO & FFA & MFA & VSSFA & MFFA \\
\hline 585 & 6.9661 & 6.8971 & 6.0667 & 6.7993 & 6.9509 \\
\hline
\end{tabular}




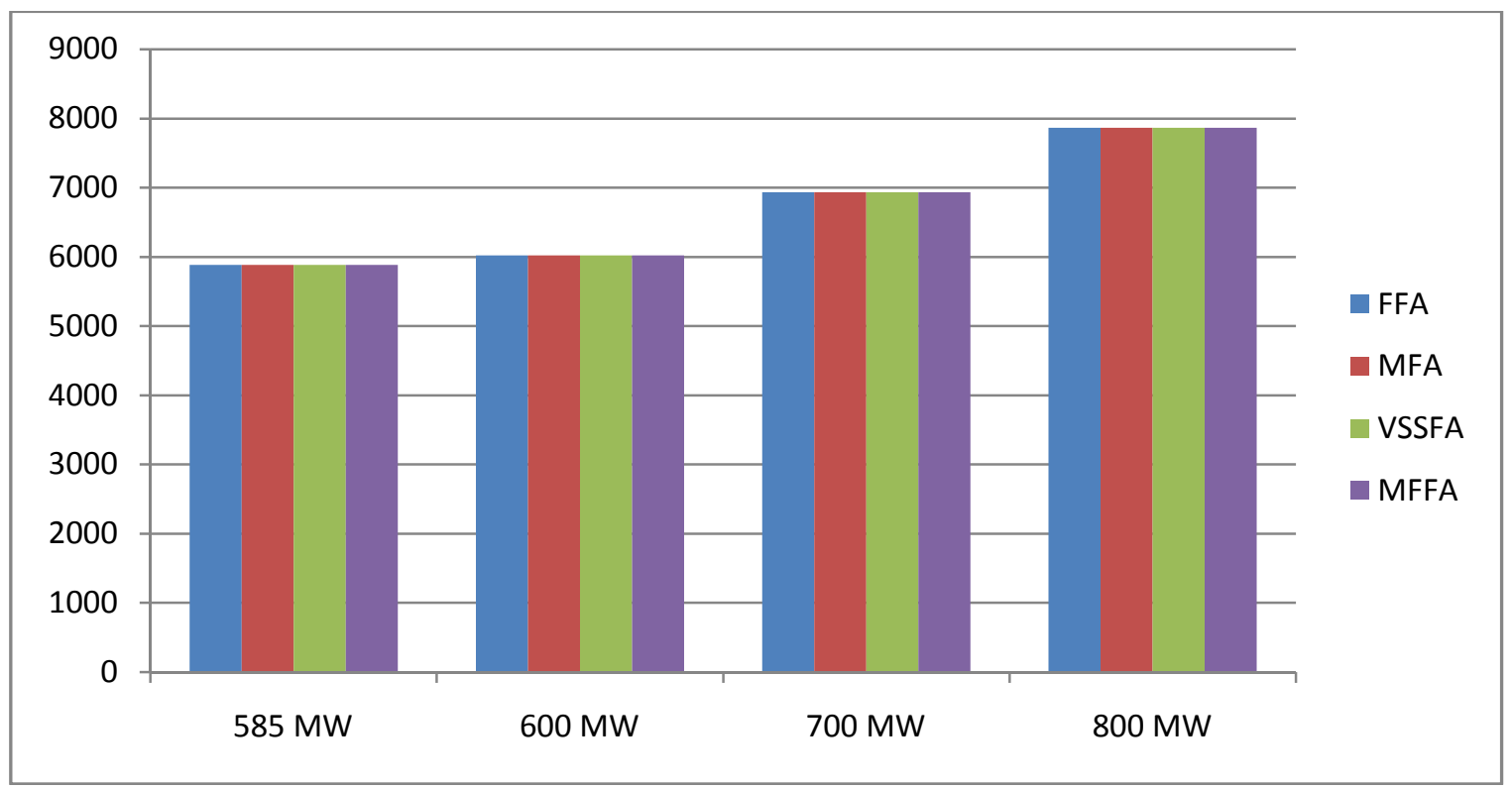

Figure 5. Comparing cost for different power demands

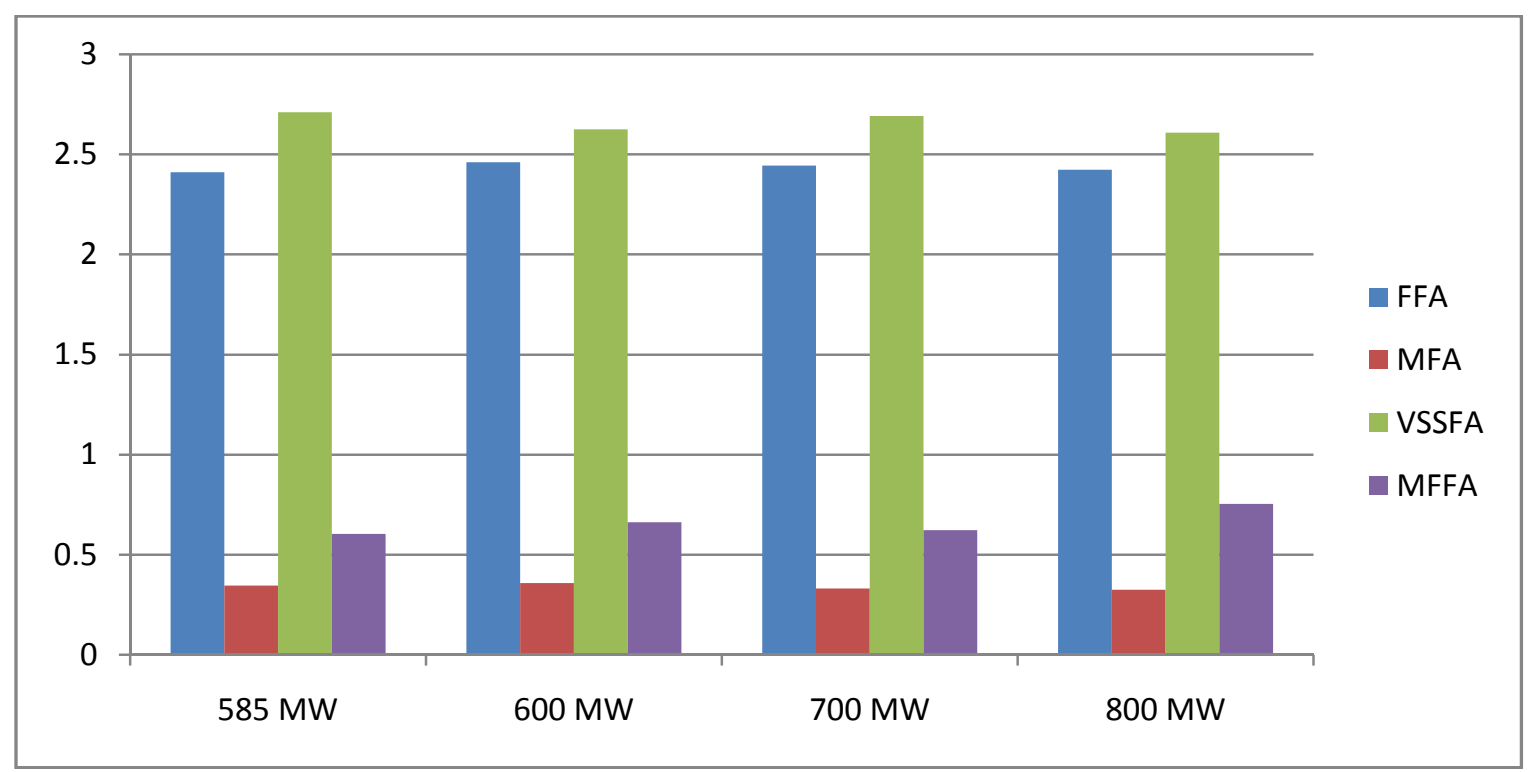

Figure 6. Comparing time for different power demands 


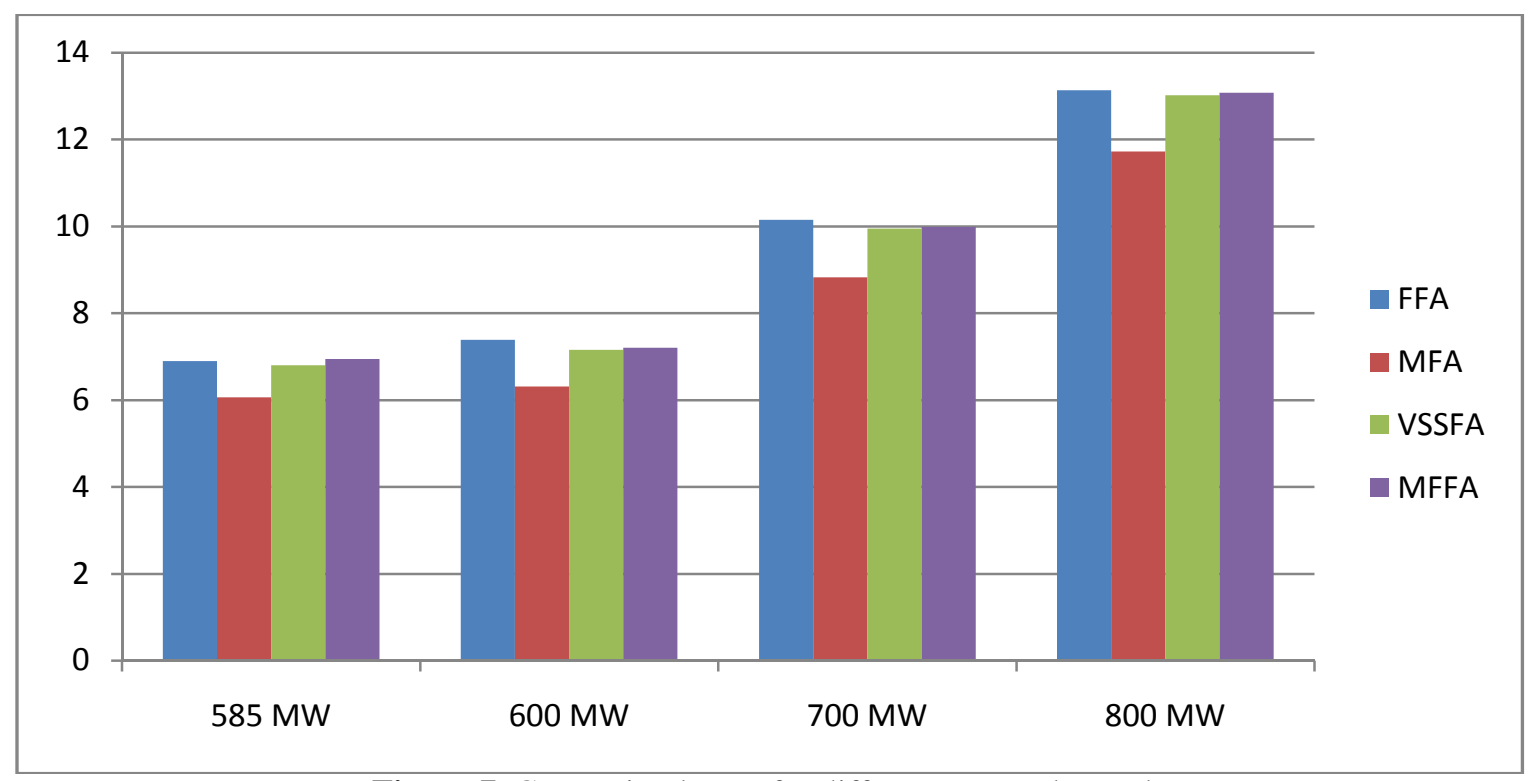

Figure 7. Comparing losses for different power demands

As shown in the above table and figures FFA achieves better solution than PSO in terms of minimum cost and execution time. The MFA outperforms the other approaches in terms of execution time and power loss. The MFA is almost 7.4 times faster than the FFA. The MFFA is almost 3.6 times faster than FFA. The VSSFA is the slowest but has less power losses compared to MFFA and FFA.

\section{Conclusions}

Since its development, firefly algorithm was utilized to solve many complex optimization problems. It was applied in the solution of economic load dispatch problem. When compared to other techniques, it has shown its superiority in achieving high quality solutions. Because FFA has some disadvantages, several modifications were proposed. In this study, three novel enhancements of FFA: modified firefly algorithm, Memetic firefly algorithm and variable step size firefly algorithmwere implemented to solve the ELD problem. The results show that the MFA capability of reaching global optimal solutions in the minimal execution time and with least transmission losses. It is superior to FFA and the other two variants. The MFFA algorithm was more successful in comparison to the FFA and VSSFA in terms of getting better solutions faster. The ELD problem is a fundamental issue. The need to generate optimum power and satisfy all system constraints in the least amount of time is important. With the noticeable difference in execution time of almost 6.5-7.5 speed gain than that of the FFA, the MFA is the most suitable method of solution of the economic load dispatch problem. It generates optimum power, at minimum operating cost and minimum transmission losses.

\section{Nomenclature}

FT

$\mathrm{a}_{\mathrm{i}}, \mathrm{b}_{\mathrm{i}}, \mathrm{c}_{\mathrm{i}}$

ET

$\alpha_{i}, \beta_{i}, \gamma_{i}, \delta_{i}, \eta_{i}$

$\mathrm{N}_{\mathrm{g}}$

ei, $f_{i}$

$\mathrm{P}_{\mathrm{i}}$,

$\mathrm{P}_{\mathrm{i}}{ }^{\text {min }}$

$\mathrm{P}_{\mathrm{i}}^{\max }$

$\mathrm{P}_{\mathrm{i}}^{0}$

$\mathrm{P}_{\mathrm{D}}$

$\mathrm{P}_{\mathrm{L}}$

$B_{i j}$

$\mathrm{UR}_{\mathrm{i}}$

$\mathrm{DR}_{\mathrm{i}}$

$\mathrm{P}_{\mathrm{i}, \mathrm{k}}$ lower

$\mathrm{P}_{\mathrm{i}, \mathrm{k}}$ upper

$\mathrm{PZ}_{\mathrm{i}}$

$\mathrm{Q}_{\mathrm{i}}$
Total cost function

Fuel cost coefficients for $i^{\text {th }}$ unit

Total Emission cost function

Emission coefficients for $i^{\text {th }}$ unit

Number of generation busses

Fuel cost coefficients for $\mathrm{i}^{\text {th }}$ unit considering valve pointeffects

Real power output from generator (i)

Minimum permitted real power output by generator (i)

Maximum permitted real power output by generator (i)

Preceding power output from generator (i)

Load demand

Power transmission losses

Loss coefficients (constants)

Up ramp rate limit by generator (i)

Down ramp rate limit by generator (i)

Lower limit of $\mathrm{k}^{\text {th }}$ prohibited operation zones for generator (i)

Upper limit of $\mathrm{k}^{\text {th }}$ prohibited operation zones for generator (i)

Number of allowed operating zones for generator (i)

Reactive power output from generator (i) 


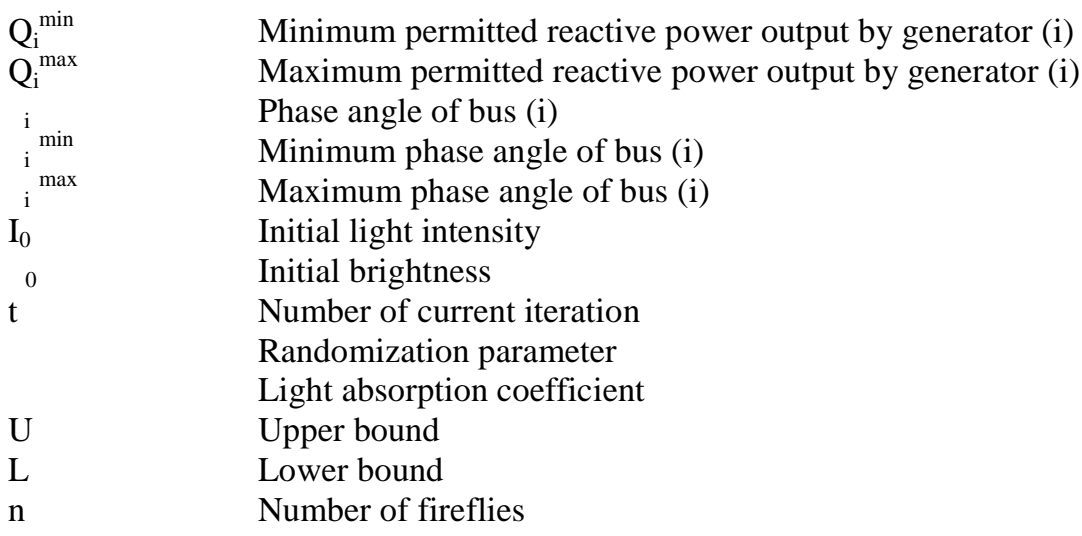

\section{References}

Dhamanda, A., Dutt, A., Prakash, S. and Bhardwaj, A.K., 2013, A traditional approach to solve economic load dispatch problem of thermal generating unit using MATLAB programming. International Journal of Engineering Research and Technology, Vol. 2, No. 9, pp. 3147-3152.

Farahani, S.M., Abshouri, A.A., Nasiri, B. and Meybodi, M., 2011. A Gaussian firefly algorithm. International Journal of Machine Learning and Computing, Vol. 1, No. 5, p. 448-453.

Fister Jr, I., Yang, X.S., Fister, I. and Brest, J., 2012. Memetic firefly algorithm for combinatorial optimization. arXiv preprint arXiv:1204.5165.

Fister, I., Yang, X.S. and Brest, J., 2013. A comprehensive review of firefly algorithms. Swarm and Evolutionary Computation, Vol. 13, pp.34-46.

Gandomi, A.H., Yang, X.S., Talatahari, S. and Alavi, A.H., 2013. Firefly algorithm with chaos. Communications in Nonlinear Science and Numerical Simulation, Vol. 18, No. 1, pp.89-98.

Jabr, R.A., Coonick, A.H. and Cory, B.J., 2000. A homogeneous linear programming algorithm for the security constrained economic dispatch problem. IEEE Transactions on Power Systems, Vol. 15, No. 3, pp.930-936.

Kazemzadeh-Parsi, M.J., 2014. A modified firefly algorithm for engineering design optimization problems. Iranian Journal of Science and Technology. Transactions of Mechanical Engineering, Vol. 38(M2), p. 403.

Lin, C.E., Chen, S.T. and Huang, C.L., 1992. A direct Newton-Raphson economic dispatch. IEEE Transactions on Power Systems, Vol. 7, No. 3, pp.1149-1154.

Moustafa, F.S., Badra, N.M. and Abdelaziz, A.Y., 2016. Solution of economic load dispatch using recent swarm-based metaheuristic algorithms: A survey. International Electrical Engineering Journal, Vol. 1, pp.2136-2147.

Noman, N. and Iba, H., 2008. Differential evolution for economic load dispatch problems. Electric Power Systems Research, Vol. 78, No. 8, pp.1322-1331.

Panigrahi, C.K., Chattopadhyay, P.K., Chakrabarti, R.N. and Basu, M., 2006. Simulated annealing technique for dynamic economic dispatch. Electric Power Components and Systems, Vol. 34, No. 5, pp. 577-586.

Reddy, K.S. and Reddy, M.D., 2012. Economic load dispatch using firefly algorithm. International Journal of Engineering Research and Applications, Vol. 2, No. 4, pp.2325-2330.

Reid, G.F. and Hasdorff, L., 1973. Economic dispatch using quadratic programming. IEEE Transactions on Power Apparatus and Systems, Vol. 6, pp.2015-2023.

Sahoo, S., Dash, K.M. and Barisal, A.K., 2014, Solution of economic load dispatch by evolutionary optimization algorithms-A comparative study. 2014 IEEE International Conference on Control, Instrumentation, Energy and Communication (CIEC), pp. $259-263$.

Subramanian, R. and Thanushkodi, K., 2013. An efficient firefly algorithm to solve economic dispatch problems. International Journal of Soft Computing and Engineering, Vol. 2, No. 1, pp.52-55.

Sudhakaran, M., Raj, P.A.D.V. and Palanivelu, T.G., 2007, November. Application of particle swarm optimization for economic load dispatch problems. IEEE International Conference on Intelligent Systems Applications to Power Systems, 2007. ISAP 2007. (pp. 1-7).

Tiwari, S., Kumar, A., Chaurasia, G.S. and Sirohi, G.S., 2013. Economic load dispatch using particle swarm optimization. International Journal of Application or Innovation in Engineering and Management, Vol. 2, No. 4, pp.476-485.

Yang, X.S., 2009, October. Firefly algorithms for multimodal optimization. International Symposium on Stochastic Algorithms (pp. 169-178). Springer Berlin Heidelberg.

Younes, M., 2013. A novel hybrid FFA-ACO algorithm for economic power dispatch. Journal of Control Engineering And Applied Informatics, Vol. 15, No. 2, pp.67-77.

Yu, S., Su, S., Lu, Q. and Huang, L., 2014. A novel wise step strategy for firefly algorithm. International Journal of Computer Mathematics, Vol. 91, No. 12, pp.2507-2513.

Yu, S., Zhu, S., Ma, Y. and Mao, D., 2015. A variable step size firefly algorithm for numerical optimization. Applied Mathematics and Computation, Vol. 263, pp.214-220. 


\section{Zhu, J., 2015. Optimization of power system operation (Vol. 47). John Wiley \& Sons.}

\section{Biographical notes}

Fatma S. Moustafa was born in Cairo, Egypt, on April 12, 1988. She received the B. Sc. degree in electrical engineering - Power and Machines department in 2010 from Faculty of Engineering, Ain Shams University, Egypt. She is currently a M. Sc. student at the Department of Engineering Physics and Mathematics, Ain Shams University, Egypt. Her areas of research include economic dispatch, artificial intelligence and optimization techniques.

Niveen M. Badra is the Head of the department of Physics and Engineering Mathematics at Faculty of Engineering, Ain Shams University. She is a Professor of Engineering Mathematics since 2008. Her interests are in Optimization and Engineering Applications, Applied Statistics with engineering applications, Numerical techniques with engineering applications, Traffic volume forecasting and Operational management.

Almoataz Y. Abdelaziz received the B.Sc. and M.Sc. degrees in electrical engineering from Ain Shams University, Egypt, in 1985 and 1990 , respectively, and the $\mathrm{Ph} . \mathrm{D}$. degree in electrical engineering according to the channel system between Ain Shams University, Egypt, and Brunel University, U.K., in 1996. He is currently a Professor of electrical power engineering at Ain Shams University. Dr. Abdelaziz is the chair of IEEE Education Society chapter in Egypt, senior editor of Ain Shams Engineering Journal, editor of Electric Power Components \& Systems Journal, editorial board member, associate editor and editorial advisory board member of several international journals and conferences. He is also a member in IET and the Egyptian Sub-Committees of IEC and CIGRE'. He has been awarded many prizes for distinct researches and for international publishing from Ain Shams University, Egypt. He has authored or coauthored more than 300 refereed journal and conference papers in his research areas which include the applications of artificial intelligence, evolutionary and heuristic optimization techniques to power system operation, planning, and control.

Received March 2017

Accepted April 2017

Final acceptance in revised form April 2017 